Check for updates

Cite this: RSC Adv., 2018, 8, 33217

\title{
Facile preparation of hybrid porous polyanilines for highly efficient $\mathrm{Cr}(\mathrm{vl})$ removal $\dagger$
}

\begin{abstract}
Wenjie Tang, Yue Wu, (D) Tingting Gao, Yingqin Wei (D) and Guowei Zhou*
In the present work, leucoemeraldine-based hybrid porous polyanilines (LHPPs) have been synthesized by the Friedel-Crafts reaction of leucoemeraldine and octavinylsilsesquioxane (OVS) for $\mathrm{Cr}(\mathrm{VI})$ removal. The resulting LHPPs were characterized by Fourier transform infrared spectroscopy, powder X-ray diffraction, thermogravimetric analysis, scanning electron microscopy and $\mathrm{N}_{2}$ adsorption-desorption. The findings indiated that the LHPPs were amorphous, with apparent surface areas $\left(S_{\mathrm{BET}}\right)$ in the range of 147 to 388 $\mathrm{m}^{2} \mathrm{~g}^{-1}$ and total volumes in the range of 0.13 to $0.44 \mathrm{~cm}^{3} \mathrm{~g}^{-1}$. $\mathrm{Cr}(\mathrm{vl})$ removal experiments displayed that the LHPPs exhibited highly efficient $\mathrm{Cr}(\mathrm{VI})$ removal performance. The maximum $\mathrm{Cr}(\mathrm{VI})$ removal capacity of LHPP-1 was $990.1 \mathrm{mg} \mathrm{g}^{-1}$ at $308 \mathrm{~K}$ and $\mathrm{pH} \mathrm{1}$, which is higher than those of other reported polyanilinebased adsorbents. The adsorption process was a spontaneous, endothermic and chemical adsorption process. The adsorption behavior agreed well with Langmuir models and pseudo second-order equations. X-ray photoelectron spectroscopy and Fourier transformed infrared (FTIR) spectroscopy analysis revealed that the highly efficient $\mathrm{Cr}(\mathrm{VI})$ removal performance can be mainly attributed to the existence of numerous amine and imine groups on the surface of the LHPPs; these can function as adsorption active sites for $\mathrm{Cr}(\mathrm{VI})$ removal through electrostatic adsorption and reduction to $\mathrm{Cr}(\mathrm{III})$ under acidic conditions. Moreover, the LHPPs exhibited excellent adsorption selectivity for $\mathrm{Cr}(\mathrm{VI})$ despite the presence of other metal ions $\left(\mathrm{K}^{+}, \mathrm{Cu}^{2+}, \mathrm{Mn}^{2+}\right)$ and anions $\left(\mathrm{NO}_{3}{ }^{-}, \mathrm{SO}_{4}{ }^{2-}\right)$. Therefore, the LHPPs have potential applications for $\mathrm{Cr}(\mathrm{VI})$ removal in industrial wastewater.
\end{abstract}

Received 22nd August 2018 Accepted 12th September 2018

DOI: $10.1039 /$ c8ra07026a

rsc.li/rsc-advances

\section{Introduction}

In the natural environment, chromium, a heavy metal ion, exists in two predominant forms. ${ }^{1} \mathrm{Cr}(\mathrm{III})$, one of the most commonly occurring forms of chromium in aqueous solutions, is less mobile, less soluble and less toxic. Moderate amounts of $\mathrm{Cr}$ (III) function as an essential micronutrient to organisms. However, excessive amounts of $\mathrm{Cr}(\mathrm{III})$ can give rise to allergic skin reactions. ${ }^{2}$ In contrast, $\mathrm{Cr}(\mathrm{VI})$, the other common form of chromium in aquatic environments, is regarded as a major contamination source. It is extremely mobile and has mutagenic, teratogenic, carcinogenic and genotoxic effects on living organisms. With the rapid development of textile manufacturing, steel fabrication, leather tanning, paint fabrication, petroleum refining and electroplating, enormous quantities of chromium are being discharged into natural water systems, threatening the environment and human health..$^{3-5}$ The World Health Organization (WHO) recommends that the maximum concentrations of $\mathrm{Cr}(\mathrm{vI})$ ion for drinking water and industrial wastewater are 0.05 and

Key Laboratory of Fine Chemicals in Universities of Shandong, School of Chemistry and Pharmaceutical Engineering, Qilu University of Technology (Shandong Academy of Sciences), Jinan 250353, Shandong, People's Republic of China. E-mail: yuewu_007@qlu.edu.cn; gwzhou@qlu.edu.cn; guoweizhou@hotmail.com

$\dagger$ Electronic supplementary information (ESI) available: Experimental and theoretical section, additional figures and tables. See DOI: 10.1039/c8ra07026a
$0.10 \mathrm{mg} \mathrm{L}^{-1}$, respectively. ${ }^{6,7}$ Therefore, in order to avoid damage from chromium, it is imperative to remove $\mathrm{Cr}(\mathrm{vI})$ and minimize the concentration of $\mathrm{Cr}(\mathrm{III})$ before chromium-contaminated water enters the ecosystem.

In the past decades, much work has been devoted to the wastewater treatment and environmental remediation of $\mathrm{Cr}(\mathrm{vI})$. The studied techniques include chemical precipitation, ion exchange, electrolysis, membrane filtration and adsorption. ${ }^{\mathbf{8 - 1 0}}$ Adsorption is the most promising approach due to its advantages of low cost, simple operation conditions, high efficiency and no secondary pollution. To date, on the basis of adsorption technology, numerous adsorbents have been developed to remove $\mathrm{Cr}(\mathrm{vI})$ from aqueous solution/wastewaters, including montmorillonite, ${ }^{\mathbf{1 1}}$ activated carbon, ${ }^{\mathbf{1 2}}$ metal and metal oxide, ${ }^{\mathbf{1 3}, \mathbf{1 4}}$ metal-organic framework-based materials, ${ }^{\mathbf{1 5}}$ boron nitride-based materials, ${ }^{16}$ double hydroxide-based nanomaterials, ${ }^{17}$ polymer-based nanocomposites, ${ }^{18}$ and bio-adsorbents. ${ }^{19}$ Although those adsorbents can effectively remove $\mathrm{Cr}(\mathrm{vI})$, most of them also have inherent disadvantages, such as lower removal capacities, high cost, and complicated and multiple steps for preparation and application. ${ }^{1}$ Therefore, with the increasing requirements for economical removal of $\mathrm{Cr}(\mathrm{vI})$ contaminated water, the development of novel adsorbents with the properties of high removal capacity, low cost, and ease of preparation and application is still a significant challenge. 
Recently, increasing attention has been given to polyaniline (PANI) because of its advantages of easy synthesis, low cost, stable chemical structure and perfect environmental compatibility. ${ }^{20}$ As a common conducting polymer, PANI has been widely applied in the fields of catalysis, energy storage, anticorrosion treatment and chemical and biological sensors. ${ }^{21-24}$ Furthermore, using PANI as an adsorbent to remedy $\operatorname{Cr}(\mathrm{vI})$ contaminated water has elicited great interest from researchers. ${ }^{25}$ It is well-known that PANI has three oxidation states: leucoemeraldine, emeraldine and pernigraniline. PANI contains abundant amine and imine groups in these three states. ${ }^{26}$ Under acidic conditions, $\mathrm{Cr}(\mathrm{vI})$ can be spontaneously reduced to $\mathrm{Cr}(\mathrm{III})$ by removing an electron from the $-\mathrm{NH}-$ unit. Meanwhile, the $-\mathrm{N}=$ unit can readily chelate the reduced $\mathrm{Cr}$ (III). Additionally, the amine and imine groups can be used as adsorption active sites to attract $\mathrm{Cr}(\mathrm{vI})$ through electrostatic attraction. ${ }^{27}$ PANI is regarded as an effective and ideal adsorbent for removal of $\mathrm{Cr}(\mathrm{vI})$ through reduction and adsorption. However, bare PANI particles readily aggregate in the processes of application and preparation, resulting in slow kinetics and low adsorption capacity. ${ }^{28,29}$ Moreover, pure PANI has poor porosity, which leads to low $\mathrm{Cr}$ (vi) removal capacity. Thus, in order to avoid the aggregation of PANI particles and greatly enhance the amounts of amine and imine groups on the adsorption material, many PANI composites, such as PANI@metal or metal oxides and PANI@carbon, have been prepared. ${ }^{30}$ Although these PANI composites can effectively prevent the aggregation of particles and improve removal of $\mathrm{Cr}(\mathrm{vI})$, It is difficult to choose a proper substrate on which to load the adsorbent. ${ }^{31,32}$ Additionally, to improve the porosity of PANI, templates, such as organic copolymers (polystyrene nanoparticle, block copolymer) and inorganic particles $\left(\mathrm{SiO}_{2}\right.$, zeolites and metal oxides), are commonly used due to their good structure controllability. ${ }^{33-37}$ After polymerization, these templates are occasionally removed to obtain micro/ nanoporous structures. Although those methods can significantly increase the porosity of polyaniline and provide relatively high removal capacities of $\mathrm{Cr}(\mathrm{vI})$, these studies often involve tedious operation processes. Furthermore, these processes cause enormous waste and sometimes introduce new heavy metal ions, resulting in secondary pollution. ${ }^{38}$ Therefore, it is urgent to develop a facile and low-cost strategy to prepare porous polyanilines with large surface areas and high $\mathrm{Cr}(\mathrm{vI})$ removal capacities. ${ }^{39}$

Herein, we report a facile preparation of leucoemeraldinebased hybrid porous polyanilines (LHPPs) through a FriedelCrafts alkylation reaction. In the reaction system, leucoemeraldine and OVS were used as the building block and crosslinker, respectively. Leucoemeraldine and OVS were connected by covalent bonds, which effectively prevents the aggregation of leucoemeraldine particles. The porous structure was directly obtained without removing the OVS. The preparation was facile and had no rigorous requirements or tedious steps. The obtained nanoporous LHPPs were amorphous polymers with apparent surface areas $\left(S_{\mathrm{BET}}\right)$ in the range of 147 to $388 \mathrm{~m}^{2} \mathrm{~g}^{-1}$. Then, the LHPPs were applied for highly efficient removal of $\mathrm{Cr}(\mathrm{vI})$; the synthetic route and the possible mechanism for $\mathrm{Cr}(\mathrm{vI})$ removal are shown in Scheme 1. To the best of our knowledge, this is the first time that the Friedel-Crafts alkylation reaction has been adopted to form porous polyanilines using leucoemeraldine and OVS as the building blocks. We investigated the removal performance of the LHPPs for $\mathrm{Cr}(\mathrm{vI})$ as well as the corresponding adsorption isotherms, adsorption kinetics, and adsorption thermodynamics. The results indicate that the nanoporous LHPPs contain abundant amine and imine groups which are mainly used as adsorption active sites for highly efficient adsorption and reduction of chromium(vi). The maximum removal capacity of LHPP-1 for $\mathrm{Cr}(\mathrm{VI})$ is $990.1 \mathrm{mg} \mathrm{g}^{-1}$ at $308 \mathrm{~K}$, which is higher than those of other reported polyaniline-based adsorbents. This work provides a promising approach to remediate $\mathrm{Cr}(\mathrm{vI})$-contaminated water which has highly promising application prospects.

\section{Experimental}

\subsection{Materials and reagents}

All chemical reagents used in the experiments were of analytical grade and were used directly without further purification unless otherwise specified. Aniline was purchased from AladdinReagent Co. Ltd (Shanghai, China). 1,2-Dichloroethane (DCE), ammonium persulfate (APS), acetone, sulphuric acid, phosphoric acid, anhydrous aluminum chloride, potassium dichromate $\left(\mathrm{K}_{2} \mathrm{Cr}_{2} \mathrm{O}_{7}\right)$, sodium dithionite and 1,5-diphenylcarbazide were all purchased from Sinopharm Chemical Reagent Co. Ltd (Shanghai, China). DCE was purified by atmospheric distillation and stored with $4 \AA$ molecular sieves. Octavinylsilsesquioxane (OVS) was prepared according to a previous literature report. ${ }^{40}$

\subsection{Preparation of emeraldine}

$4.6 \mathrm{~mL}$ aniline and $50 \mathrm{~mL}$ hydrochloric acid solution $\left(2 \mathrm{~mol} \mathrm{~L}^{-1}\right)$ were charged into a $250 \mathrm{~mL}$ round bottom flask in an ice-water bath. After stirring for 10 minutes, $25 \mathrm{~mL}$ ammonium persulfate ( $2 \mathrm{~mol} \mathrm{~L}^{-1}$ ) was added dropwise to the reaction system. The aqueous solution became blackish green. After continuing the reaction for $4 \mathrm{~h}$, the product was filtered and washed with deionized water, then transferred into $50 \mathrm{~mL}$ ammonia and stirred for $24 \mathrm{~h}$. The product was filtered and washed with deionized water until the $\mathrm{pH}$ reached 7 . Finally, the black powder was dried in vacuo at $60{ }^{\circ} \mathrm{C}$ for $12 \mathrm{~h}$.

\subsection{Preparation of leucoemeraldine}

Emeraldine $(4.0 \mathrm{~g})$, sodium dithionite $(8.0 \mathrm{~g})$ and $40 \mathrm{~mL}$ deionized water were added to a $250 \mathrm{~mL}$ round-bottom flask. Under ambient temperature, after agitation for $6 \mathrm{~h}$, another $4 \mathrm{~g}$ portion of sodium dithionite was added. While maintaining the reaction conditions, the mixture was continuously stirred for $12 \mathrm{~h}$. Then, the powder was decanted into $500 \mathrm{~mL}$ of deionized water. After filtration, the brown powder was dried in vacuo at room temperature and stored in a desiccator under vacuum. 


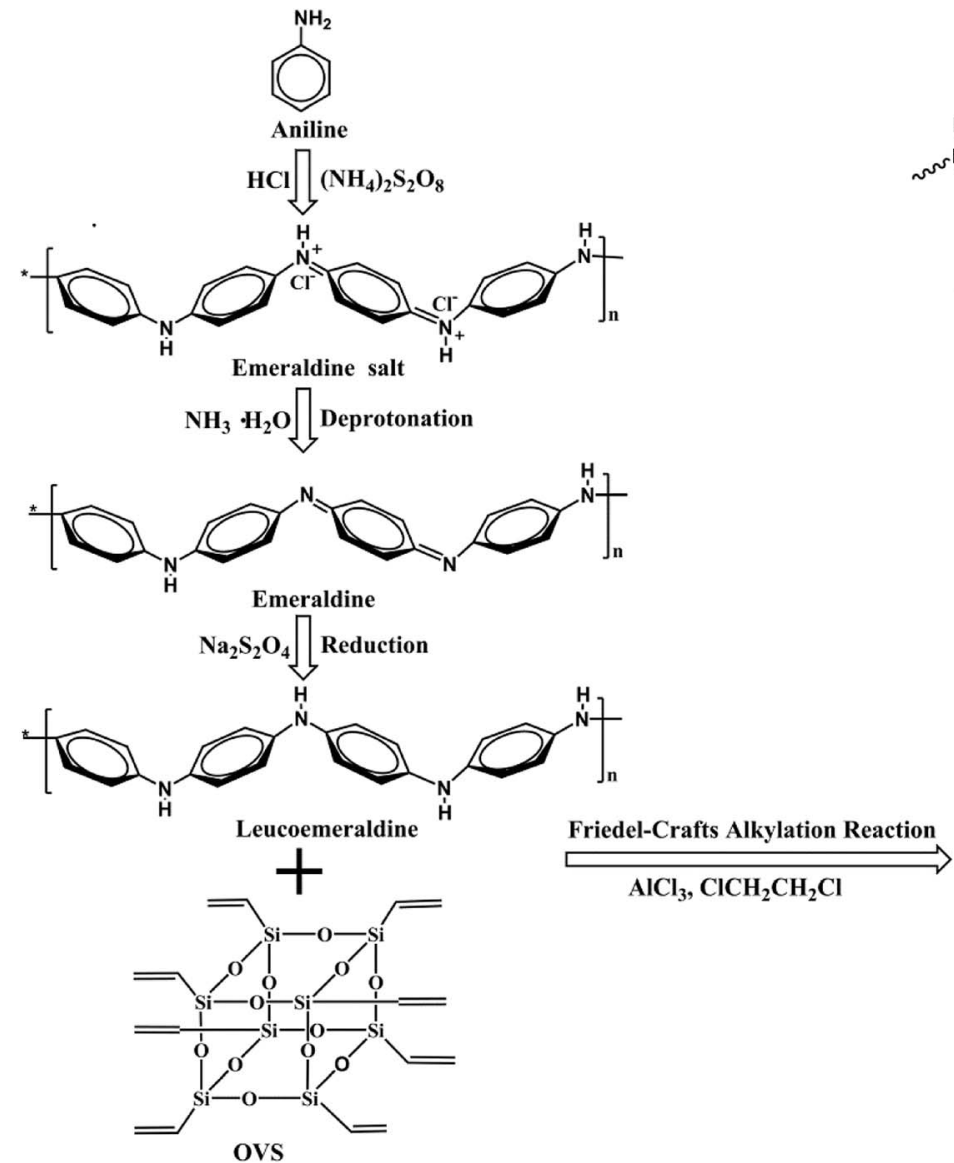

ovs
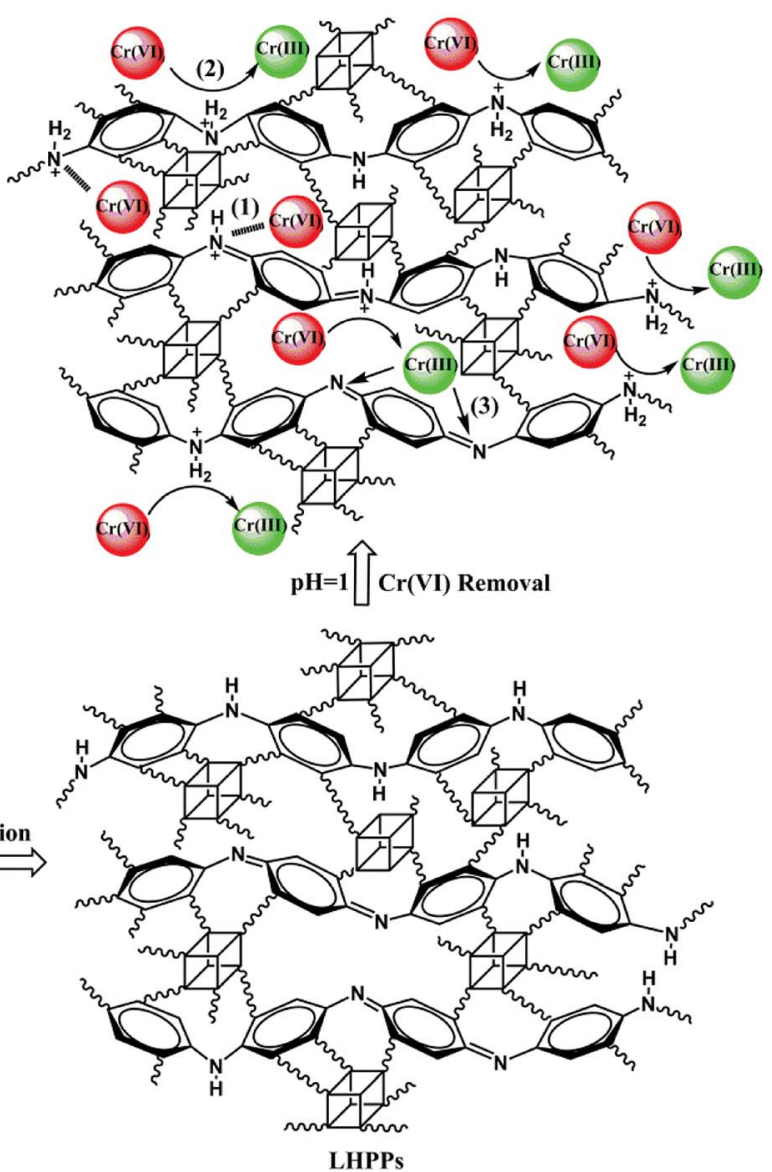

Scheme 1 Synthetic route for the LHPPs and proposed mechanism for $\mathrm{Cr}(\mathrm{vI})$ removal: (1) electrostatic attraction, (2) reduction, (3) chelation.

\subsection{Synthesis of leucoemeraldine-based hybrid porous polyanilines (LHPP-1, LHPP-2 and LHPP-3)}

$1.0 \mathrm{~g}$ leucoemeraldine and a certain amount of OVS $(0.3 \mathrm{~g}$ for LHPP-1; $0.5 \mathrm{~g}$ for LHPP-2; $0.7 \mathrm{~g}$ for LHPP-3) were poured into a $50 \mathrm{~mL}$ oven-dried one-necked flask. The reaction system was degassed and argon was input three times. Then, anhydrous $\mathrm{AlCl}_{3}(2.00 \mathrm{~g}, 15 \mathrm{mmol})$ and $20 \mathrm{~mL}$ DCE were quickly loaded. The mixture was vigorously agitated at ambient temperature for $0.5 \mathrm{~h}$ and refluxed for $24 \mathrm{~h}$. Then, the reaction system was cooled to room temperature. The product was washed with anhydrous methanol and collected by filtration. The powder was further washed with deionized water. Then, the obtained polymers were purified under a Soxhlet extractor with tetrahydrofuran and methanol for $48 \mathrm{~h}$, respectively. Finally, the black powder was dried in vacuo at $60{ }^{\circ} \mathrm{C}$ for $12 \mathrm{~h}$.

\subsection{Adsorption experiment}

A certain amount of $\mathrm{K}_{2} \mathrm{Cr}_{2} \mathrm{O}_{7}$ was dissolved in deionized water to prepare a concentration gradient of $\mathrm{Cr}(\mathrm{vI})$ oxyanion solutions (60 to $200 \mathrm{mg} \mathrm{L}^{-1}$ ). Then, $30 \mathrm{mg}$ as-synthesized porous polyaniline was dispersed in $200 \mathrm{~mL}$ of $\mathrm{Cr}(\mathrm{vI})$ solution. The mixture was shaken at $180 \mathrm{rpm}$ with a thermostat oscillator. At a pre-set time, a $5 \mathrm{~mL}$ aliquot of the mixture was taken out and the supernatant was obtained by immediate centrifugation. The equilibrium $\mathrm{Cr}(\mathrm{vI})$ concentration was determined using a UV-vis spectrophotometer with the diphenylcarbazide method, and the equilibrium adsorption capacity was calculated by the following equation: ${ }^{41}$

$$
Q_{\mathrm{e}}=\frac{\left(C_{0}-C_{\mathrm{e}}\right) \times V}{m}
$$

where $C_{0}$ and $C_{\mathrm{e}}$ are the initial and equilibrium concentrations of the $\mathrm{Cr}(\mathrm{vI})$ solution, respectively; $V$ is the volume of the $\mathrm{Cr}(\mathrm{vI})$ oxyanion solution; and $m$ is the mass of the adsorbent.

Each adsorption experiment was conducted thrice to evaluate the adsorption performance of the LHPPs. The effects of factors such as the level of acidity (pH 1 to 6), contact time ( 0 to $72 \mathrm{~h}$ ), initial concentration of $\mathrm{Cr}(\mathrm{vI})$ oxyanions $\left(0\right.$ to $\left.200 \mathrm{mg} \mathrm{L}^{-1}\right)$ and temperature $(303 \mathrm{~K}, 308 \mathrm{~K}$ and $313 \mathrm{~K})$ were investigated.

\section{Results and discussion}

\subsection{Characterization of the LHPPs}

Emeraldine was prepared according to a previous literature report. ${ }^{42}$ The resulting emeraldine was deprotonated with ammonia and was then characterized by FT-IR spectroscopy (Fig. S1(b) †). The peaks at 3400, 1590, 1495, 1307 and $1160 \mathrm{~cm}^{-1}$ were ascribed to the $\mathrm{N}-\mathrm{H}$ stretching vibration and $\mathrm{C}=\mathrm{N}$ stretching modes of the quinonoid rings, the $\mathrm{C}=\mathrm{C}$ stretching 
vibration of the benzenoid rings, and the $\mathrm{C}-\mathrm{N}$ stretching mode and $\mathrm{N}=\mathrm{Q}=\mathrm{N}$ quinonoid stretching vibration, respectively. ${ }^{43}$ After reduction with aqueous sodium dithionite, the intensities of the peaks at 1590 and $1160 \mathrm{~cm}^{-1}$ in leucoemeraldine decreased to different degrees (Fig. S1(c) $\dagger$ ). The results indicated that emeraldine was reduced to leucoemeraldine. ${ }^{\mathbf{4 4}}$ Emeraldine and leucoemeraldine were also characterized by UV-vis spectroscopy (Fig. S2 $\dagger$ ). The UV-vis spectra displayed that the peak of emeraldine at $640 \mathrm{~nm}$ disappeared after reduction with sodium dithionite; this phenomenon further confirmed that emeraldine had been transformed into leucoemeraldine. These results agreed with a previous report. ${ }^{45}$

Fig. S1 $(d-f) \dagger$ displays the FT-IR spectra of LHPP-1, LHPP-2 and LHPP-3, respectively. In comparison with the patterns of leucoemeraldine and OVS, the stretching vibration peaks of the $\mathrm{C}=\mathrm{C}$ bending vibration in LHPP-1 to LHPP-3 were slightly red shifted; the value became about $1485 \mathrm{~cm}^{-1}$. A new peak at about $2926 \mathrm{~cm}^{-1}$ appeared in the spectra of LHPP-1, LHPP-2 and LHPP-3, and the intensities of the peaks increased to different levels. All these phenomena indicate that there were different contents of $\mathrm{CH}_{2}$ groups in LHPP-1 to LHPP-3 after leucoemeraldine was reacted with OVS. ${ }^{46,47}$ These results confirmed that leucoemeraldine participated in the Friedel-Crafts reaction.

Powder X-ray diffraction (XRD) was also used to analyze the crystallographic orders of emeraldine, leucoemeraldine, OVS, LHPP-1, LHPP-2 and LHPP-3. As shown in Fig. 1, the sharp diffraction peaks at $2 \theta=15.1^{\circ}, 20.7^{\circ}$ and $25.5^{\circ}$ were ascribed to the (011), (020) and (200) crystal planes of emeraldine, confirming the existence of polyaniline in emeraldine form. ${ }^{48}$ After reduction with aqueous sodium dithionite, no diffraction peaks emerged in the pattern of leucoemeraldine; this predictable result indicates that the leucoemeraldine was amorphous. ${ }^{\mathbf{4 9}}$ Additionally, the diffraction patterns of LHPP-1, LHPP-2 and LHPP-3 displayed that no distinct intensified diffraction peaks appeared, and only one broad peak appeared at approximately $2 \theta=23^{\circ}$ in each polymer. These findings imply that the hybrid

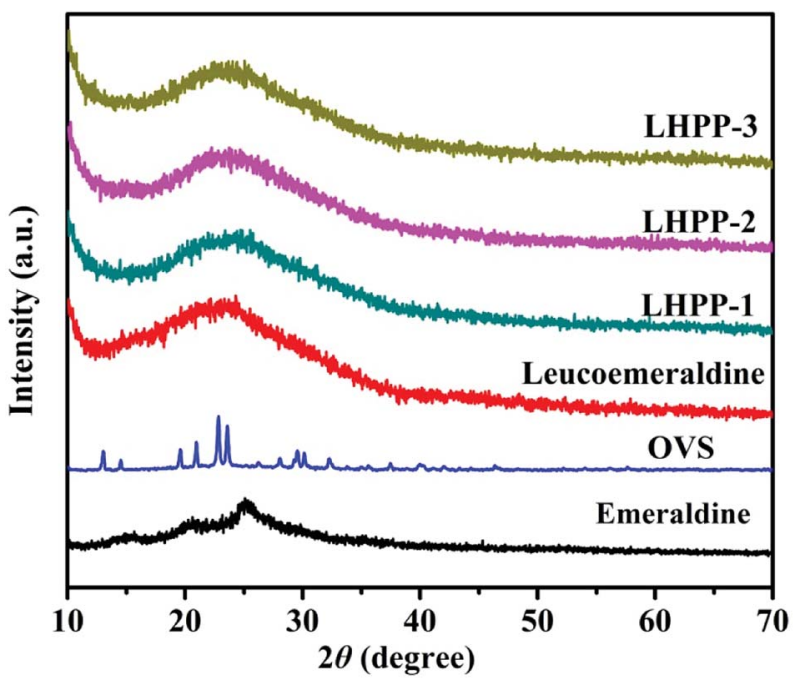

Fig. 1 XRD patterns of emeraldine, leucoemeraldine, OVS, LHPP-1, LHPP-2 and LHPP-3 nanoporous polyanilines of LHPP-1, LHPP-2 and LHPP-3 were amorphous and did not possess long-range ordered structures. $^{49}$

The particle sizes and internal morphologies of the resulting nanoporous polymers were investigated by FE-SEM. As shown in Fig. 2(a), leucoemeraldine was composed of densely aggregated fibrous and granular particles. ${ }^{50,51}$ After reaction with OVS, the hierarchical porous polymers were obtained (Fig. 2(b)(d)). ${ }^{52}$ The resulting hybrid polymers also comprised entangled irregular particles. The particle sizes of all these polymers were in the range of $100 \mathrm{~nm}$ to several tens of micrometers.

The thermal stabilities of leucoemeraldine, LHPP-1, LHPP-2 and LHPP-3 were investigated by TGA under $\mathrm{N}_{2}$ atmosphere (Fig. S3†). The initial weight loss in the range of $40{ }^{\circ} \mathrm{C}$ to $120{ }^{\circ} \mathrm{C}$ was attributed to atmospheric water. ${ }^{53}$ Compared with pure leucoemeraldine, from $120{ }^{\circ} \mathrm{C}$ to $300{ }^{\circ} \mathrm{C}$, the weight losses of LHPP-1, LHPP-2 and LHPP-3 were related to removal of the $\mathrm{HCl}$ doping anions which were produced in the processes of preparation and purification. ${ }^{53}$ From $300{ }^{\circ} \mathrm{C}$ to $1000{ }^{\circ} \mathrm{C}$, the mass losses of leucoemeraldine and LHPP-1, LHPP-2 and LHPP-3 were ascribed to decomposition of the polymer chains. ${ }^{53}$

Fig. 3(a and b) displays the $\mathrm{N}_{2}$ sorption isotherms and pore size distributions (PSDs) of LHPP-1, LHPP-2 and LHPP-3. The three polymers exhibited steep $\mathrm{N}_{2}$ uptakes at relatively low pressure $\left(P / P_{0}<0.001\right)$, indicating the presence of abundant micropores in their structures. ${ }^{49}$ At relatively high pressure, a slight hysteresis loop and a gradually increasing uptake were obtained. These results imply that these polymers possessed a certain number of mesopores and a few macropores. ${ }^{49}$ It is also worth noting that the $\mathrm{N}_{2}$ uptake isotherm of LHPP-3 was slightly steeper than the other two isotherms at relatively high pressures, suggesting that the contributions of the mesopores and macropores in LHPP-3 were greater than those in LHPP-1 and LHPP-2. The PSD curves of LHPP-1 and LHPP-2 illustrate that the two hybrid polyanilines possessed uniform micropores centered at about $1.26 \mathrm{~nm}$ and a narrower distribution of mesopores from $2.1 \mathrm{~nm}$ to $10 \mathrm{~nm}$; the PSD curve of LHPP-3 exhibits that it possessed bimodal micropores centered at about $1.26 \mathrm{~nm}$ and a broader distribution of mesopores and macropores from $2.1 \mathrm{~nm}$ to $100 \mathrm{~nm}$.
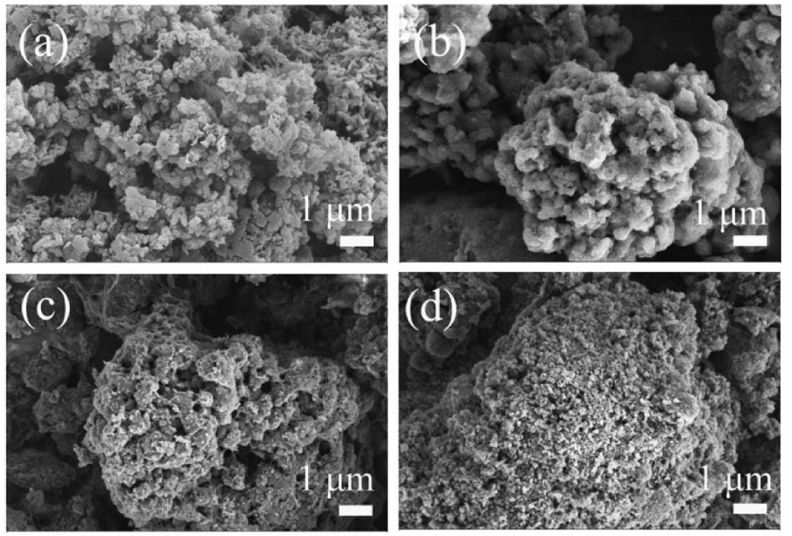

Fig. 2 FE-SEM images of (a) leucoemeraldine; (b) LHPP-1; (c) LHPP-2; and (d) LHPP-3. 

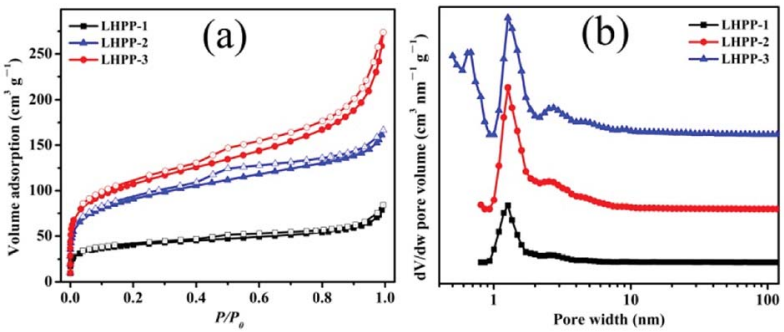

Fig. 3 (a) $\mathrm{N}_{2}$ sorption isotherms of LHPP-1, LHPP-2 and LHPP-3; (b) pore size distributions of LHPP-1, LHPP-2 and LHPP-3.

The detailed porosity data of the three polymers are shown in Table 1 . The apparent BET specific surface areas $\left(S_{\mathrm{BET}}\right)$ of LHPP1 to LHPP-3 were 147, 330, and $388 \mathrm{~m}^{2} \mathrm{~g}^{-1}$, respectively. The total pore volumes $\left(V_{\text {total }}\right)$ for LHPP-1 to LHPP-3 were $0.13,0.26$ and $0.42 \mathrm{~cm}^{3} \mathrm{~g}^{-1}$ calculated at $P / P_{0}=0.99$, respectively. These high $S_{\text {BET }}$ values and hierarchical pore structures can not only support more active adsorption sites but can also facilitate the transport of adsorbates in interconnected pore structure systems, thus enhancing the adsorption capacity. ${ }^{38}$

\section{2 $\mathrm{Cr}(\mathrm{vI})$ removal performance of the LHPPs}

3.2.1 Effects of $\mathbf{p H}$. The acidity level has a significant effect on the adsorption capacity of $\mathrm{Cr}(\mathrm{vI})$. The solution $\mathrm{pH}$ can dramatically affect the existing forms of $\mathrm{Cr}(\mathrm{vI})$ and the surface charges of the polymer adsorbents, thereby affecting the removal capacity of the adsorbents. In view of the fact that LHPP-1, LHPP-2 and LHPP-3 possess similar chemical structures and physicochemical properties and that LHPP-3 has the highest surface area, LHPP-3 was firstly chosen as the sample to investigate the $\mathrm{Cr}(\mathrm{vi})$ removal capacity at different $\mathrm{pH}$ values. Adsorption experiments were performed with an initial $\mathrm{Cr}(\mathrm{vI})$ concentration of $200 \mathrm{mg} \mathrm{L}^{-1}$, a contact time of $24 \mathrm{~h}$, a temperature of $298 \mathrm{~K}, 30 \mathrm{mg}$ of LHPP-3, and a $\mathrm{pH}$ range of 1 to 6 adjusted with $1 \mathrm{~mol} \mathrm{~L}^{-1} \mathrm{HCl}$ and $0.1 \mathrm{~mol} \mathrm{~L}^{-1} \mathrm{NaOH}$ aqueous solutions. As displayed in Fig. 4, the Cr(vi) removal capacity of LHPP-3 was pH-responsive; that is, the adsorption capacity gradually increased with decreasing $\mathrm{pH}$ and reached its maximum of $558.7 \mathrm{mg} \mathrm{g}^{-1}$ at $\mathrm{pH}$ 1. These results can be attributed to two aspects. On the one hand, LHPP-3 was constructed from OVS and leucoemeraldine. The resulting polymer was rich in $-\mathrm{NH}-$ and $-\mathrm{N}=$ groups in addition to its high surface area. At lower $\mathrm{pH}$ values, these groups are apt to be protonated and exist in the forms of $-\mathrm{NH}_{2}{ }^{+}-$and $-\mathrm{NH}^{+}=$. Thus,
LHPP-3 possessed positive charges. Meanwhile, when the $\mathrm{pH}$ was in the range of 1 to 6 , the primary existing forms of $\mathrm{Cr}(\mathrm{vI})$ ions were $\mathrm{HCrO}_{4}{ }^{-}$and $\mathrm{Cr}_{2} \mathrm{O}_{7}{ }^{2-}$. Thus, these positive charges produced strong electrostatic attractions with $\mathrm{HCrO}_{4}{ }^{-}$and $\mathrm{Cr}_{2} \mathrm{O}_{7}{ }^{2-}$, resulting in the successful removal of $\mathrm{Cr}(\mathrm{vI}) .{ }^{41}$ The contents of the protonated $-\mathrm{NH}_{2}{ }^{+}-$and $-\mathrm{NH}^{+}=$groups increased with decreasing $\mathrm{pH}$ value. Consequently, the adsorption capacity of $\mathrm{Cr}(\mathrm{vI})$ increased with decreasing $\mathrm{pH} .{ }^{54} \mathrm{On}$ the other hand, at relatively lower $\mathrm{pH}$ values, the main existing form of $\mathrm{Cr}(\mathrm{vI})$ is $\mathrm{HCrO}_{4}{ }^{-}$, which can be readily reduced to $\mathrm{Cr}$ (III) due to its higher redox potential. ${ }^{55}$ In the subsequent experiments, the $\mathrm{pH}$ was adjusted to 1 .

3.2.2 The effects of the component ratios. To study the effects of the composition of the LHPPs on their $\mathrm{Cr}(\mathrm{VI})$ removal performance and to obtain the optimum adsorption capacity, OVS, polyaniline, LHPP-1, LHPP-2 and LHPP-3 were used to conduct $\mathrm{Cr}(\mathrm{vI})$ adsorption experiments. The adsorption experiments were performed with adsorbent dosage: $30 \mathrm{mg}$, initial concentration: $200 \mathrm{mg} \mathrm{L}^{-1}$, temperature: $298 \mathrm{~K}$, contact time: $72 \mathrm{~h}$, and shaking rate: $180 \mathrm{rpm}$. The equilibrium removal capacities of OVS and polyaniline were 0 and $10.35 \mathrm{mg} \mathrm{g}^{-1}$, respectively. As shown in Fig. 5, the equilibrium removal capacities of LHPP-1, LHPP-2 and LHPP-3 were 963.7, 707.6 and $670.4 \mathrm{mg} \mathrm{g}^{-1}$, respectively. The removal capacity for $\mathrm{Cr}(\mathrm{vI})$ decreased with increasing mass ratio of OVS and leucoemeraldine. These findings can be explained as follows: (i) in one aspect, as the mass ratios of OVS and leucoemeraldine increased, the $S_{\mathrm{BET}}$ of the LHPPs increased, which resulted in increased removal capacity for $\mathrm{Cr}(\mathrm{vI})$; (ii) in another aspect, with increasing mass ratio of OVS and leucoemeraldine, the content of leucoemeraldine units in the polymer structure decreased, resulting in lower contents of $-\mathrm{NH}-$ and $-\mathrm{N}=$ groups in the polyaniline structure. ${ }^{27}$ Therefore, the amount of adsorption active sites decreased, leading to decreased removal capacity of $\mathrm{Cr}(\mathrm{vI})$. However, the decreases in the removal capacities originating from the gradually lower contents of $-\mathrm{NH}-$ and $-\mathrm{N}=$ groups were larger than the increases in the removal capacities arising from the gradually increasing $S_{\mathrm{BET}}$; thus, finally, the removal capacities for $\mathrm{Cr}(\mathrm{vI})$ gradually decreased with increasing mass ratio of OVS and leucoemeraldine. In the subsequent experiments, LHPP-1 was selected as the sample.

3.2.3 Effects of contact time and adsorption kinetics study. The effects of contact time on the removal capacity were also investigated. The adsorption experiments were performed with an oscillating rate of $180 \mathrm{rpm}$, a temperature of $308 \mathrm{~K}, 30 \mathrm{mg}$ LHPP-1 and an initial Cr(vI) concentration of $200 \mathrm{mg} \mathrm{L}^{-1}$. The

Table 1 The porosity data for LHPP-1 to LHPP-3

\begin{tabular}{lllllll}
\hline Sample & OVS/leucoemeraldine $\left(\mathrm{g} \mathrm{g}^{-1}\right)$ & $S_{\mathrm{BET}}{ }^{a} / \mathrm{m}^{2} \mathrm{~g}^{-1}$ & $S_{\text {micro }} / \mathrm{m}^{2} \mathrm{~g}^{-1}$ & $V_{\text {total }}^{c} / \mathrm{cm}^{3} \mathrm{~g}^{-1}$ & $V_{\text {micro }}{ }^{d} / \mathrm{cm}^{3} \mathrm{~g}^{-1}$ & $V_{\text {micro }} / V_{\text {total }}$ \\
\hline LHPP-1 & $0.3 / 1.0$ & 147 & 123 & 0.13 & 0.05 & 0.38 \\
LHPP-2 & $0.5 / 1.0$ & 330 & 267 & 0.26 & 0.14 \\
LHPP-3 & $0.7 / 1.0$ & 388 & 220 & 0.42 & 0.10
\end{tabular}

${ }^{a}$ Surface areas calculated from $\mathrm{N}_{2}$ adsorption isotherms using the BET method. ${ }^{b}$ Microporous surface areas calculated from $\mathrm{N}_{2}$ adsorption isotherms using the $t$-plot method. ${ }^{c}$ Total pore volumes calculated at $P / P_{0}=0.99 .{ }^{d}$ Micropore volumes derived using the $t$-plot method based on the Halsey thickness equation. 


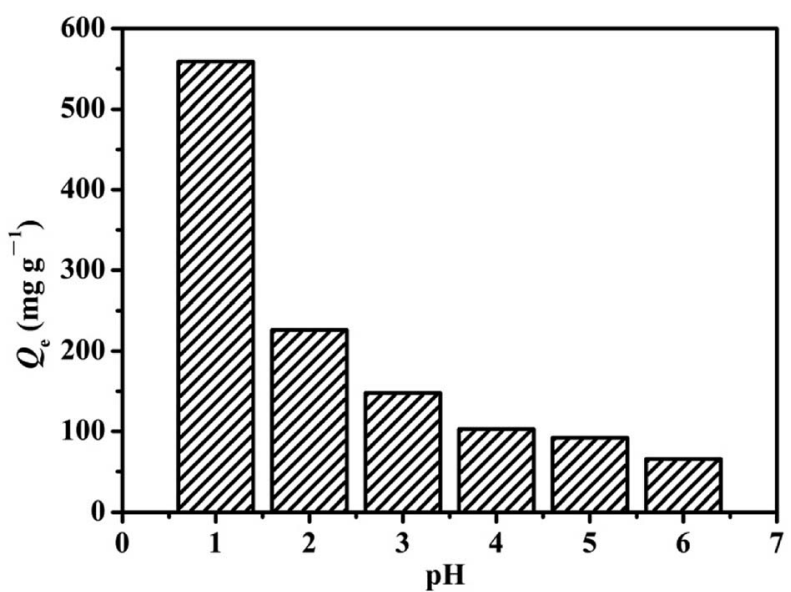

Fig. 4 Effects of initial $\mathrm{pH}$ on the $\mathrm{Cr}(\mathrm{vI})$ removal performance of LHPP3.

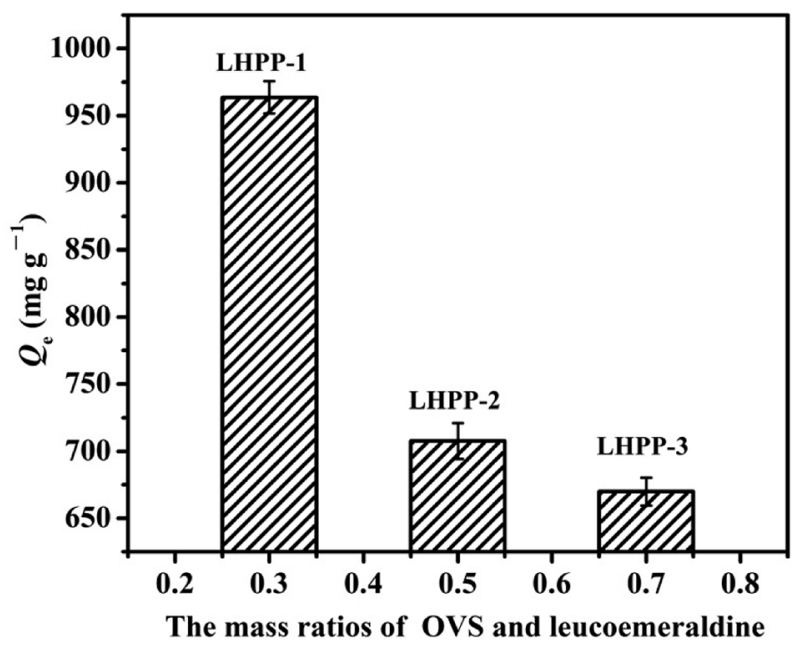

Fig. 5 Effects of the mass ratio of OVS and leucoemeraldine on the $\mathrm{Cr}(\mathrm{VI})$ removal performance of the samples.

relationship between the removal capacity at time $t\left(Q_{t}\right)$ and the contact time is shown in Fig. 6(a). In the initial $5 \mathrm{~h}$, LHPP-1 exhibited a steep adsorption for $\mathrm{Cr}(\mathrm{vI})$, and the removal capacity was about $626.5 \mathrm{mg} \mathrm{g}^{-1}$. Subsequently, the removal capacity increased slowly until the maximum removal capacity of approximately $990 \mathrm{mg} \mathrm{g}^{-1}$ was obtained at about $48 \mathrm{~h}$, indicating that the adsorption equilibrium was reached. This phenomenon is due to the continuously decreasing adsorption sites and the high concentration of $\mathrm{Cr}(\mathrm{vI})$ ions as well as the gradually increasing repulsive interactions. ${ }^{56}$ In the initial stage of adsorption, at a lower $\mathrm{pH}$ and a high concentration of $\mathrm{Cr}(\mathrm{vI})$, many Cr(vI) ions could be quickly removed by LHPP-1 in a short time because LHPP-1 possesses sufficient adsorption active sites and a high surface area. As a large number of adsorption sites became occupied by $\mathrm{Cr}(\mathrm{VI})$ and $\mathrm{Cr}(\mathrm{III})$ ions, the number of adsorption sites and the concentration of $\mathrm{Cr}(\mathrm{vI})$ ions both decreased. In addition, the repulsive interactions between the $\mathrm{Cr}(\mathrm{vI})$ ions in solution and the negative charges in the solid phase significantly increased. ${ }^{56}$ Therefore, after several hours of adsorption, it was difficult for the fewer remaining adsorption sites to uptake $\mathrm{Cr}(\mathrm{vI})$ ions from solution, resulting in a long time to reach equilibrium.

To better understand the adsorption behavior of LHPP-1, its $\mathrm{Cr}(\mathrm{vI})$ adsorption kinetics were further evaluated by the pseudofirst-order kinetic model and pseudo-second-order kinetic model, which assume that one $\mathrm{Cr}(\mathrm{vI})$ can occupy one or two adsorption sites on the surface of the adsorbent, respectively. ${ }^{57}$

Pseudo-first-order:

$$
\log \left(Q_{\mathrm{e}}-Q_{t}\right)=\log Q_{\mathrm{e}}-\frac{K_{1} t}{2.303}
$$

Pseudo-second-order:

$$
\frac{t}{Q_{t}}=\frac{1}{K_{2} Q_{\mathrm{e}}{ }^{2}}+\frac{1}{Q_{\mathrm{e}}}
$$

where $Q_{t}$ is the adsorption capacity of LHPP-1 at time $t(\mathrm{~h})$ and $K_{1}$ and $K_{2}$ are the pseudo-first-order and pseudo-second-order adsorption rate constants, respectively.

Fig. 6(b and c) depicts the adsorption kinetics plots where the data were fitted by the pseudo-first-order and pseudosecond-order models. The detailed data are listed in Table 2. Obviously, the correlation coefficient $\left(R^{2}=0.995\right)$ fitted with the pseudo second-order model was higher that fitted with the pseudo first-order model $\left(R^{2}=0.646\right)$, indicating that $\operatorname{Cr}(\mathrm{vI})$ adsorption in this experiment was governed by chemical
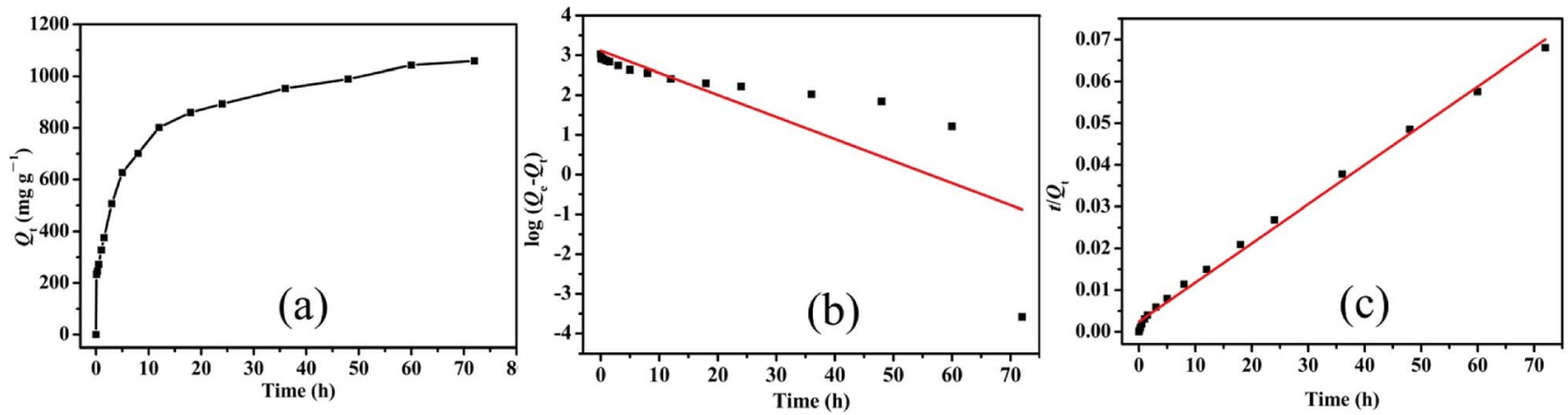

Fig. 6 (a) Relationship of $Q_{t}$ and contact time with $\mathrm{Cr}(\mathrm{VI})$ removal by LHPP-1 and adsorption kinetics studies with the (b) pseudo-first order model and (c) pseudo-second order model. 
Table 2 The detailed data of the adsorption kinetic equations

\begin{tabular}{lllllllll}
\hline & \multicolumn{3}{c}{ Pseudo-first-order } & & \multicolumn{3}{c}{ Pseudo-second-order } \\
\cline { 2 - 4 } Adsorbate & $K_{1}$ & $Q_{\mathrm{e}}$ & $R^{2}$ & & $K_{2}$ & $Q_{\mathrm{e}}$ & $R^{2}$ \\
\hline $\mathrm{Cr}(\mathrm{vI})$ & 0.128 & 1304.2 & 0.646 & 0.000366 & 1064.9 & 0.995
\end{tabular}

adsorption and that one $\mathrm{Cr}(\mathrm{vI})$ could occupy two adsorption sites. ${ }^{57}$

3.2.4 Effects of initial concentration and adsorption isotherm study. To explore the effects of the initial concentration of $\mathrm{Cr}(\mathrm{vI})$ on the removal performance of LHPP-1, adsorption experiments were carried out with a temperature of $308 \mathrm{~K}$, $30 \mathrm{mg}$ of LHPP-1, and initial $\mathrm{Cr}(\mathrm{VI})$ concentrations in the range of 60 to $200 \mathrm{mg} \mathrm{g}^{-1}$. The results are shown in Fig. 7(a). At lower initial concentrations, the equilibrium adsorption capacity $\left(Q_{\mathrm{e}}\right)$ increased with increasing initial concentration of $\mathrm{Cr}(\mathrm{vI})$. This is probably because higher concentrations of $\mathrm{Cr}(\mathrm{vI})$ can shorten the mean free path and increase the collisions between $\mathrm{Cr}(\mathrm{vI})$ and the adsorption sites of LHPP-1, thereby promoting the transportation of $\mathrm{Cr}(\mathrm{vI})$ ions from the solution to the adsorbents. With continuously increasing initial concentration of $\mathrm{Cr}(\mathrm{vI})$, the adsorption sites supported by LHPP-1 could not satisfy the requirements to remove $\mathrm{Cr}(\mathrm{vI})$ from the solution; then, $Q_{\mathrm{e}}$ reached its maximum value of $1003 \mathrm{mg} \mathrm{g}^{-1}$. Subsequently, $Q_{\mathrm{e}}$ did not change further despite the increase of the initial concentration of $\mathrm{Cr}(\mathrm{vI})$. This phenomenon is due to the high $S_{\mathrm{BET}}$ and the electrostatic attraction between the adsorbent-adsorbate system. ${ }^{41}$

The Langmuir and Freundlich isothermal models were both used to simulate the adsorption process. The Langmuir model assumes that there are no interactions between the adsorbed molecules and that monolayer adsorption occurs (chemisorption). The Freundlich model is an empirical model on the basis of sorption on heterogeneous surfaces, assuming that the stronger binding sites are basically occupied and the binding strength decreases with increasing degree of site occupation. The adsorption isotherm data were calculated by the Langmuir and Freundlich isotherm models, respectively. The linear forms were shown by the following equations: ${ }^{58}$
Langmuir isotherm model:

$$
\frac{C_{\mathrm{e}}}{Q_{\mathrm{e}}}=\frac{1}{K_{\mathrm{L}} Q_{\mathrm{m}}}+\frac{C_{\mathrm{e}}}{Q_{\mathrm{m}}}
$$

Freundlich isotherm model:

$$
\log Q_{\mathrm{e}}=\log K_{\mathrm{F}}+\frac{1}{n} \log C_{\mathrm{e}}
$$

The dimensionless quantity of the Langmuir isotherm model, termed the separation factor $\left(R_{\mathrm{L}}\right)$, was calculated by the following equation:

$$
R_{\mathrm{L}}=\frac{1}{1+K_{\mathrm{L}} C_{0}}
$$

where $C_{\mathrm{e}}\left(\mathrm{mg} \mathrm{L}^{-1}\right)$ and $C_{0}\left(\mathrm{mg} \mathrm{L}^{-1}\right)$ represent the equilibrium concentration and initial concentration; $Q_{\mathrm{e}}\left(\mathrm{mg} \mathrm{g}^{-1}\right)$ and $Q_{\mathrm{m}}$ $\left(\mathrm{mg} \mathrm{g}^{-1}\right)$ denote the adsorption capacity at equilibrium and the maximum adsorption capacity in the calculation, respectively; $K_{\mathrm{L}}$ and $K_{\mathrm{F}}$ are the adsorption constants of the Langmuir and Freundlich adsorption isotherm models, respectively; and $n$ is the adsorption intensity.

Fig. 7(b) and (c) depicts the adsorption equilibrium data fitted by Langmuir and Freundlich isotherm models. The detailed data calculated by the two isotherm models are listed in Table 3. The correlation coefficient $\left(R^{2}\right)$ calculated by the Langmuir isotherm model was 0.999 , which is higher than that of the Freundlich model $\left(R^{2}=0.404\right)$. This result indicates that the $\mathrm{Cr}(\mathrm{vI})$ ion removal process in this work conformed well with the Langmuir isotherm model and that the adsorption process was monolayer chemisorption. ${ }^{3}$ Moreover, the value of $R_{\mathrm{L}}$ was 0.898 and fell in the range of 0 to 1 , suggesting the favorable uptake of $\mathrm{Cr}(\mathrm{vI}){ }^{58}$ The calculated $Q_{\mathrm{m}}$ was $990.1 \mathrm{mg} \mathrm{g}^{-1}$, which is close to the experimental data. The maximum removal capacity of LHPP-1 is higher than those of other reported polyanilinebased adsorbents and other adsorbents, as shown in Table 4.

3.2.5 Effects of temperature and adsorption thermodynamic study. Thermodynamic studies of $\mathrm{Cr}(\mathrm{VI})$ removal by LHPP-1 were performed at 303, 308 and $313 \mathrm{~K}$ to investigate the nature of the removal process. Fig. 8(a) shows the relationship between the equilibrium adsorption quantity and the solution
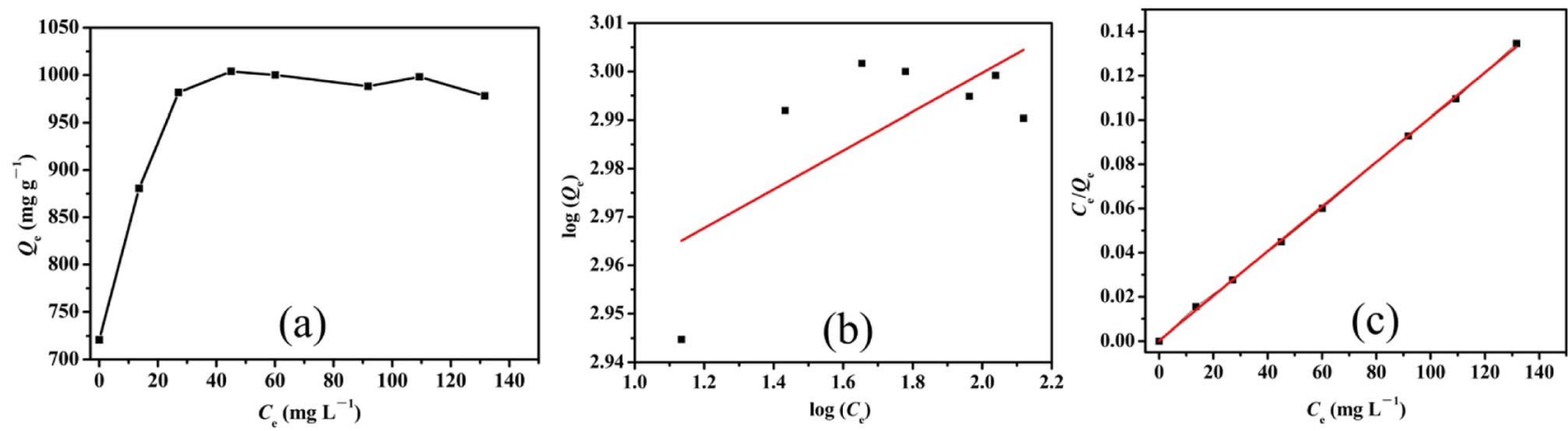

Fig. 7 (a) Effects of the initial concentration on $\mathrm{Cr}(\mathrm{VI})$ removal by LHPP-1 and adsorption isotherm studies with the (b) Freundlich isotherm model and (c) Langmuir isotherm model. 
Table 3 The detailed data of the adsorption isotherm models

\begin{tabular}{|c|c|c|c|c|c|c|c|}
\hline \multirow[b]{2}{*}{ Adsorbate } & \multicolumn{4}{|c|}{ Langmuir isotherm model } & \multicolumn{3}{|c|}{$\begin{array}{l}\text { Freundlich } \\
\text { isotherm model }\end{array}$} \\
\hline & $K_{\mathrm{L}}$ & $Q_{\mathrm{m}}$ & $R_{\mathrm{L}}$ & $R^{2}$ & $K_{\mathrm{F}}$ & $1 / n$ & $R^{2}$ \\
\hline $\mathrm{Cr}(\mathrm{vI})$ & 0.0005 & 990.1 & 0.898 & 0.999 & 831 & 0.04 & 0.4 \\
\hline
\end{tabular}

temperature. With increasing temperature, the equilibrium adsorption capacity gradually increased. This is mainly attributed to Brownian motion; that is, with increasing temperature, the molecular motion became more vigorous, resulting in greatly increased collision probability between the adsorption active site and $\operatorname{Cr}(\mathrm{vI})$. The adsorption thermodynamic parameters were calculated by the following equations: ${ }^{60}$

$$
\begin{aligned}
& \Delta G^{0}=-R T \ln K_{\mathrm{c}} \\
& \ln K_{\mathrm{c}}=\frac{\Delta S^{0}}{R}-\frac{\Delta H^{0}}{R T}
\end{aligned}
$$

where $\Delta G^{0}, \Delta S^{0}$ and $\Delta H^{0}$ are the standard Gibbs free energy change, standard entropy change and standard enthalpy change, respectively. $K_{\mathrm{c}}$ refers to the ratio of the $\mathrm{Cr}(\mathrm{vI})$ equilibrium adsorption quantity and equilibrium concentration. $R$ is the gas constant $\left(8.314 \mathrm{~J} \mathrm{~mol}^{-1} \mathrm{~K}^{-1}\right) . T(\mathrm{~K})$ is the absolute temperature.

Fig. 8(b) displays the relationship between $\ln K_{\mathrm{c}}$ and $1 / T$ calculated by the van't Hoff equation (eqn (8)). Through linear fitting, the slopes and intercepts were obtained. With the aid of these data, the values of $\Delta H^{0}$ and $\Delta S^{0}$ were calculated (Table 5). Obviously, the value of $\Delta H^{0}$ is positive, indicating that the nature of the adsorption process is endothermic. Additionally, the positive value of $\Delta S^{0}$ indicates that the affinity of LHPP-1 and $\operatorname{Cr}(\mathrm{vI})$ increased the randomness at the solid-solution interface. Moreover, the negative values of $\Delta G^{0}$ exhibit that the adsorption process is spontaneous, implying that high temperature is beneficial for the adsorption process.

Table 4 Comparison of maximum adsorption capacities for $\mathrm{Cr}(\mathrm{VI})$ with

\begin{tabular}{|c|c|c|}
\hline Adsorbent & $\begin{array}{l}\text { Maximum adsorption } \\
\text { capacity }\left(\mathrm{mg} \mathrm{g}^{-1}\right)\end{array}$ & Ref. \\
\hline pTSA-Pani@GO-CNT & 142.85 & 59 \\
\hline PNEANI/Ch-HCl & 229.8 & 7 \\
\hline PANI/HA & 173.0 & 8 \\
\hline ZVI@C@PANI & 508 & 55 \\
\hline Polyaniline@Ni $(\mathrm{OH})_{2}$ & 625 & 60 \\
\hline EPS@PANI & 913.2 & 38 \\
\hline PANI/H-TNB & 156.94 & 61 \\
\hline $\mathrm{PVP} / \mathrm{MoS}_{2}$ & 142.24 & 62 \\
\hline CHFs & 112.71 & 63 \\
\hline LDHs@MoS 2 & 76.3 & 64 \\
\hline MPC-300 & 21.23 & 65 \\
\hline nZVI/MCM & 164.31 & 66 \\
\hline C@La- $\mathrm{TiO}_{2}$ & 50.5 & 67 \\
\hline LHPP-1 & 990.1 & This work \\
\hline
\end{tabular}
other reported work
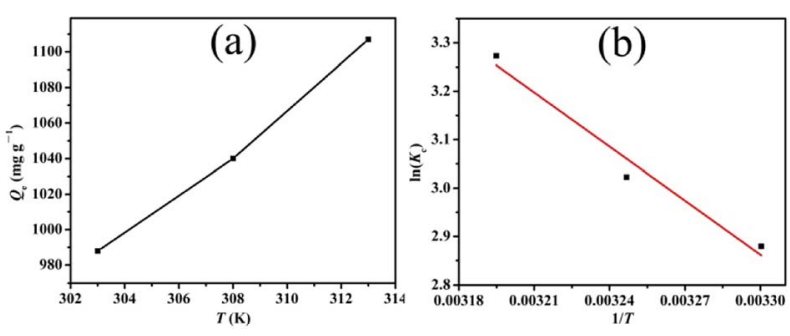

Fig. 8 (a) The relationship of equilibrium adsorption capacity and solution temperature and (b) the van't Hoff equation model for the adsorption of $\mathrm{Cr}(\mathrm{vI})$ by LHPP-1.

3.2.6 Effects of coexisting ions. In industrial waste water, $\mathrm{Cr}$ (vI) anion inevitably coexists with other metal cations or anions, such as $\mathrm{K}^{+}, \mathrm{Cu}^{2+}, \mathrm{Mn}^{2+}, \mathrm{NO}_{3}{ }^{-}$and $\mathrm{SO}_{4}{ }^{2-}$. These ions compete slightly with $\mathrm{Cr}(\mathrm{vI})$ ions and affect the $\mathrm{Cr}(\mathrm{vI})$ adsorption. ${ }^{68}$ Therefore, it is worth studying the competitive adsorption effects of these coexisting ions on the removal performance of the adsorbent. The competitive adsorption experiments were performed under the conditions of $\mathrm{pH} 1$, a temperature of 308 $\mathrm{K}$, an oscillating rate of $180 \mathrm{r}$, an adsorbent dosage of $30 \mathrm{mg}$, an initial $\mathrm{Cr}(\mathrm{vI})$ concentration of $200 \mathrm{mg} \mathrm{L}^{-1}$, and a contact time of $72 \mathrm{~h}$. The molar ratio of the $\mathrm{Cr}(\mathrm{vI})$ anion and the coexisting ions was set at $1: 1$. The results are displayed in Fig. 9. In the absence of coexisting ions in the mixture, the equilibrium adsorption capacity of $\mathrm{Cr}(\mathrm{vI})$ anion was $1040.55 \mathrm{mg} \mathrm{g}^{-1}$. Meanwhile, in the presence of $\mathrm{K}^{+}, \mathrm{Cu}^{2+}$ and $\mathrm{Mn}^{2+}$ ions, the equilibrium adsorption amounts of $\mathrm{Cr}$ (vI) slightly decreased to 1014.95, 965.57 and $925.66 \mathrm{mg} \mathrm{g}^{-1}$, respectively. These findings suggest that the metal ion species present in the reaction solution competed for binding onto the sorption sites of the LHPP-1 surface. The probable reason is that in the presence of the coexisting cations, the nitrogen-containing groups in LHPP-1 inevitably chelated with the cations possessing empty orbits, such as $\mathrm{Cu}^{2+}$ and $\mathrm{Mn}^{2+}$, resulting in a decrease in the number of adsorption active sites for $\mathrm{Cr}(\mathrm{vI})$ anion..$^{28}$ In the presence of both $\mathrm{NO}_{3}{ }^{-}$and $\mathrm{SO}_{4}{ }^{2-}$ anions, the equilibrium adsorption amounts $\mathrm{Cr}(\mathrm{vI})$ slightly decreased to 1020.61 and $926.66 \mathrm{mg} \mathrm{g}^{-1} \cdot \mathrm{SO}_{4}{ }^{2-}$ affected the $\mathrm{Cr}(\mathrm{vI})$ removal capacity more significantly than $\mathrm{NO}_{3}{ }^{-}$; this may be due to the consumption of $\mathrm{SO}_{4}{ }^{2-}$ ions by the surface sites of LHPP-1 and, hence, a decrease of the available adsorption sites for $\mathrm{Cr}(\mathrm{vI})$ ions. Furthermore, $\mathrm{SO}_{4}{ }^{2-}$ ions decrease the surface positive charge and thereby decrease the electrostatic interactions between the surface and the $\operatorname{Cr}(\mathrm{vI})$ species. ${ }^{68}$ Generally, regardless of the presence of these coexisting cations and anions, the equilibrium adsorption amounts for $\mathrm{Cr}(\mathrm{vI})$ were all greater than $920 \mathrm{mg} \mathrm{g}^{-1}$; these results indicate that the affinity between $\mathrm{Cr}(\mathrm{vI})$ and LHPP-1 is very strong and

Table 5 Thermodynamic parameters for $\mathrm{Cr}(\mathrm{vl})$ removal

\begin{tabular}{lllll}
\hline Adsorbent & $\Delta H^{0}\left(\mathrm{~kJ} \mathrm{~mol}^{-1}\right)$ & $\Delta S^{0}\left(\mathrm{~J} \mathrm{~mol}^{-1} \mathrm{~K}^{-1}\right)$ & $\Delta G^{0}\left(\mathrm{~kJ} \mathrm{~mol}^{-1}\right)$ & $T(\mathrm{~K})$ \\
\hline \multirow{2}{*}{ LHPP-1 } & \multirow{2}{*}{30.98} & \multirow{2}{*}{126.02} & -7.25 & 303 \\
& & & -7.74 & 308 \\
& & & -8.52 & 313
\end{tabular}




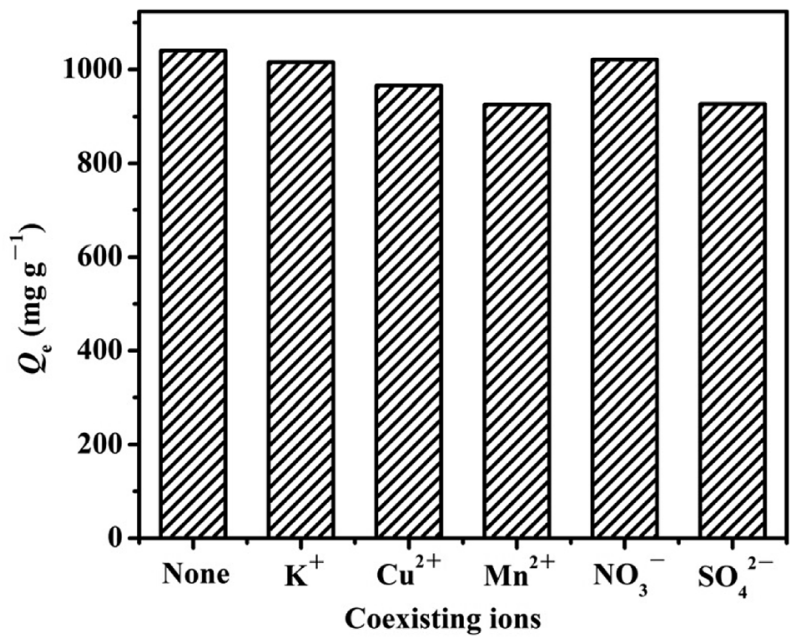

Fig. 9 Effects of coexisting ions on the adsorption of $\mathrm{Cr}(\mathrm{VI})$ by LHPP-1.

that LHPP-1 exhibits selective properties for removing $\mathrm{Cr}(\mathrm{vI})$ ions.

3.2.7 Reusability of the adsorbent. Adsorption-desorption experiments were conducted for four cycles to verify the reusability of the LHPPs. The experiments were performed under the conditions of $\mathrm{pH} 1$, a temperature of $308 \mathrm{~K}$, an oscillating rate of $180 \mathrm{r}$, an initial $\mathrm{Cr}(\mathrm{vI})$ concentration of $200 \mathrm{mg} \mathrm{L}^{-1}$, and a contact time of $24 \mathrm{~h} .100 \mathrm{~mL}$ of $0.5 \mathrm{~mol} \mathrm{~L}^{-1}$ phytic acid solution was used to regenerate the adsorbent. Fig. 10 shows the relationship between the regeneration cycle number of LHPPs and the corresponding $\mathrm{Cr}(\mathrm{VI})$ removal capacity. The $\mathrm{Cr}(\mathrm{vI})$ adsorption amounts for LHPP-1, LHPP-2 and LHPP-3 were 803.62 to $867.44 \mathrm{mg} \mathrm{g}^{-1}, 578.87$ to $638.36 \mathrm{mg} \mathrm{g}^{-1}$ and 546.37 to $604.69 \mathrm{mg} \mathrm{g}^{-1}$, respectively. The equilibrium removal capacities of the LHPPs slightly decreased with increasing cycle number. LHPP-1, LHPP-2 and LHPP-3 exhibited excellent reusability and possessed $92.64 \%, 90.64 \%$ and $90.35 \%$ retention after the fourth cycle, respectively. The decreases in the adsorption amounts can be ascribed to incomplete desorption of the adsorbate from the surface of the adsorbent. ${ }^{61}$

\subsection{Adsorption mechanism study}

XPS and FTIR were used to investigate the mechanism of $\mathrm{Cr}(\mathrm{vI})$ removal from aqueous solution at pH 1 by LHPP-1. Fig. 11(a) displays the FTIR spectra of LHPP-1 before and after $\operatorname{Cr}(\mathrm{vI})$ adsorption. It can be seen that the intensity of the peak of LHPP1 at $1590 \mathrm{~cm}^{-1}$ increased after $\mathrm{Cr}(\mathrm{vI})$ removal, indicating that the content of the $\mathrm{C}=\mathrm{N}$ groups increased in the polymer structures. The results exhibited that some units of - NH-Ph- in LHPP-1 were oxidized to units of $-\mathrm{N}=\mathrm{Ph}$ - during the $\mathrm{Cr}(\mathrm{vI})$ removal process. ${ }^{61}$ As shown in Fig. 11(b), before adsorption, the LHPP-1 was composed of C 1s, N 1s, O 1s and Si 2p; after adsorption, the peak position of $\mathrm{Cr} 2 \mathrm{p}$ was found to be in the range of 571.2 to $594.4 \mathrm{eV}$, indicating that $\mathrm{Cr}(\mathrm{vr})$ was successfully adsorbed by LHPP-1. Fig. 11(c) shows the characteristic binding energy peak of $\mathrm{Cr} 2 \mathrm{p}$. The binding energy peaks at 588.48 and $578.98 \mathrm{eV}$ correspond to $\mathrm{Cr} 2 \mathrm{p}$ of $\mathrm{Cr}(\mathrm{vI})$, and the binding energy peaks at 586.78 and $577.08 \mathrm{eV}$ correspond to $\mathrm{Cr} 2 \mathrm{p}$ of $\mathrm{Cr}(\mathrm{III})$. The

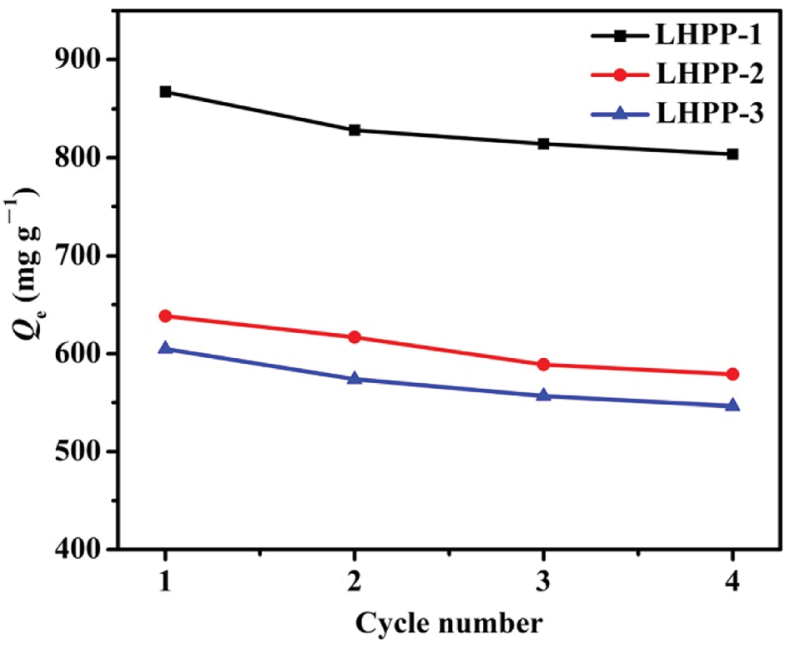

Fig. 10 Relationship between the cycle number of LHPPs and the corresponding $\mathrm{Cr}(\mathrm{VI})$ adsorption.

results were attributed to the partial reduction of $\operatorname{Cr}(\mathrm{vI})$ in solution to $\mathrm{Cr}(\mathrm{III})$ by LHPP-1 during the removal process (Scheme 1). ${ }^{55}$ Comparison of the peak areas of $\mathrm{Cr}(\mathrm{III})$ and the total $\mathrm{Cr}$ revealed a favorable reduction, with $\mathrm{Cr}(\mathrm{III})$ accounting for $68.9 \%$; this indicates the good reducibility of LHPP-1. ${ }^{41}$ When the $\mathrm{pH}$ was in the range of 1 to $6, \mathrm{Cr}(\mathrm{VI})$ existed mainly in the forms of $\mathrm{HCrO}_{4}{ }^{-}$and $\mathrm{Cr}_{2} \mathrm{O}_{7}{ }^{2-}$ anions. The reduction of $\mathrm{Cr}(\mathrm{VI})$ to $\mathrm{Cr}(\mathrm{III})$ in acidic medium on the surface of the adsorbent is governed by the following equations. ${ }^{69}$

$$
\begin{aligned}
& \mathrm{Cr}_{2} \mathrm{O}_{7}^{2-}+14 \mathrm{H}^{+}+6 \mathrm{e}^{-} \rightarrow 2 \mathrm{Cr}^{3+}+7 \mathrm{H}_{2} \mathrm{O} \\
& \mathrm{HCrO}_{4}^{-}+7 \mathrm{H}^{+}+3 \mathrm{e}^{-} \rightarrow \mathrm{Cr}^{3+}+4 \mathrm{H}_{2} \mathrm{O}
\end{aligned}
$$

The - NH- of LHPP-1 acted as the electron donor and $-\mathrm{NH}^{+}=/-\mathrm{NH}_{2}{ }^{+}$- provided the $\mathrm{H}^{+}$in the reduction process. ${ }^{38,55}$
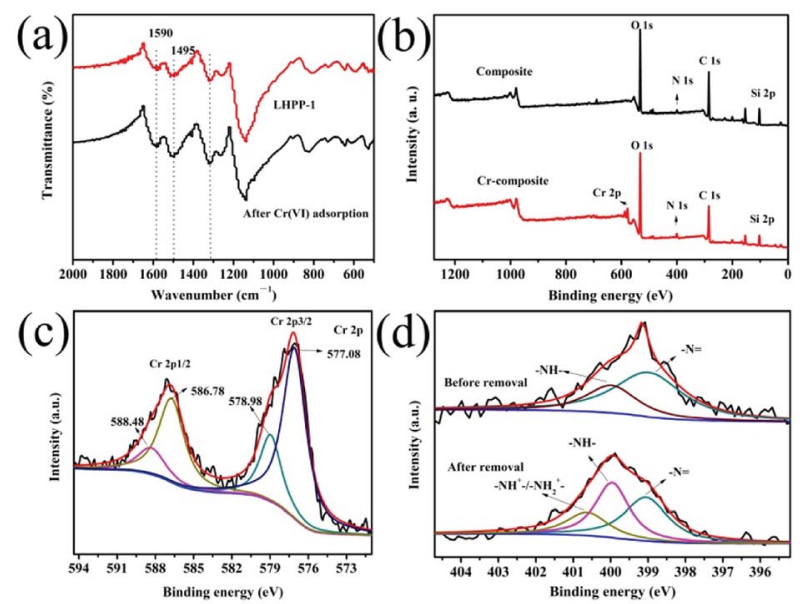

Fig. 11 (a) FTIR spectra of LHPP-1 before and after Cr(vI) removal, (b) XPS spectra of LHPP-1 before and after $\mathrm{Cr}(\mathrm{VI})$ removal, high resolution XPS spectra of $\mathrm{Cr} 2 \mathrm{p}$ (c) and N 1s (d) for LHPP-1 before and after $\mathrm{Cr}(\mathrm{vI})$ removal. 
Fig. 11(d) displays the high-resolution XPS of the $\mathrm{N}$ 1s peak before and after $\mathrm{Cr}(\mathrm{vI})$ adsorption in solution. Before adsorption, two binding energy peaks existed at 399.1 and $400.0 \mathrm{eV}$, corresponding to the $-\mathrm{N}=$ and $-\mathrm{NH}$ - groups, respectively. After adsorption, a new binding energy peak of $-\mathrm{NH}^{+}=/-\mathrm{NH}_{2}{ }^{+}$ appeared at $400.7 \mathrm{eV} .^{70}$ The reason for the new peak of $-\mathrm{NH}^{+}=/-$ $\mathrm{NH}_{2}{ }^{+}$- is that some $-\mathrm{N}=$ and $-\mathrm{NH}-$ groups were readily protonated to $-\mathrm{NH}^{+}=/-\mathrm{NH}_{2}{ }^{+}$- under the acidic conditions. This provided sufficient adsorption sites for efficient adsorption of $\mathrm{Cr}(\mathrm{vI}) .{ }^{41}$ Based on the analysis, the removal mechanism of the LHPPs for $\mathrm{Cr}(\mathrm{vI})$ was attributed to three aspects (Scheme 1). Firstly, $\mathrm{Cr}(\mathrm{vI})$ was adsorbed by the adsorbent via electrostatic attraction interactions with $-\mathrm{NH}^{+}=/-\mathrm{NH}_{2}{ }^{+}$-; secondly, most of the $\mathrm{Cr}(\mathrm{vI})$ accepted electrons from $-\mathrm{NH}$ - units and were then reduced to $\mathrm{Cr}(\mathrm{III})$, while the units of $-\mathrm{NH}$ - were oxidized to units of $-\mathrm{N}=$; third, most of the $\mathrm{Cr}(\mathrm{III})$ cations were chelated with units of $-\mathrm{N}=\mathrm{Ph}=\mathrm{N}$ - and adsorbed by LHPP-1. ${ }^{71}$ In this process, the electrostatic attraction and simultaneous reduction are chiefly responsible for the highly efficient $\mathrm{Cr}(\mathrm{vI})$ removal performance in this work. This result was similar to other reports. $^{72}$

\section{Conclusions}

In summary, we have demonstrated a facile method to prepare hybrid porous polyanilines for highly efficient $\mathrm{Cr}(\mathrm{vI})$ removal. During the synthesis of the hybrid porous polyanilines, commonly used leucoemeraldine and OVS were directly used as the building unit and the cross-linker, respectively. The apparent surface areas of the as-synthesized LHPPs were in the range of 147 to $388 \mathrm{~m}^{2} \mathrm{~g}^{-1}$ and the total volumes were in the range of 0.13 to $0.44 \mathrm{~cm}^{3} \mathrm{~g}^{-1}$. The porosities of the LHPPs could be tuned by changing the mass ratio of OVS to leucoemeraldine. The $\mathrm{Cr}(\mathrm{vI})$ removal performance of the LHPPs was investigated by batch adsorption experiments. The results indicated that the $\mathrm{Cr}(\mathrm{vI})$ removal capacity was strongly dependent on the solution $\mathrm{pH}$, the composition of the adsorbent, the initial concentration of $\mathrm{Cr}(\mathrm{vI})$, the contact time and the adsorption temperature. The adsorption process was endothermic and spontaneous and conformed to the Langmuir isotherm model as well as the pseudo-second-order kinetic model. Under the conditions of pH 1.0 and $308 \mathrm{~K}$, LHPP-1 possessed the optimum $\mathrm{Cr}(\mathrm{vI})$ removal performance. The maximum removal capacity was $990.1 \mathrm{mg} \mathrm{g}^{-1}$, which is higher than those of other polyanilinebased adsorbents. The presence of numerous amine and imine groups as well as the porous structure of LHPP-1 were confirmed to be responsible for its high removal capacity for $\mathrm{Cr}(\mathrm{vI})$. The effects of coexisting ion experiments revealed that LHPP-1 displays excellent adsorption selectivity to $\operatorname{Cr}(\mathrm{vI})$ regardless of the presence of cations $\left(\mathrm{K}^{+}, \mathrm{Cu}^{2+}, \mathrm{Mn}^{2+}\right)$ and anions $\left(\mathrm{NO}^{3-}, \mathrm{SO}_{4}{ }^{2-}\right)$. Therefore, the present study may provide a new approach for the development of polyaniline-based adsorbents for environmental remediation.

\section{Conflicts of interest}

There are no conflicts to declare.

\section{Acknowledgements}

This research was supported by the Joint Funds of Shandong Provincial Natural Science Foundation and Colleges and Universities of Shandong Province (ZR2017LEM013), the National Natural Science Foundation of China (Grant No. 51372124, 51572134, 51503108), the Program for Scientific Research Innovation Team in Colleges and Universities of Shandong Province and Shandong Provincial Key Laboratory of Fluorine Chemistry and Chemical Materials.

\section{Notes and references}

1 R. Karthik and S. Meenakshi, Synthesis, Int. J. Biol. Macromol., 2015, 72, 235.

2 M. Bhaumik, S. Agarwal, V. K. Gupta and A. Maity, J. Colloid Interface Sci., 2016, 470, 257.

3 H. Wang, X. Yuan, Y. Wu, X. Chen, L. Leng, H. Wang, H. Li and G. Zeng, Chem. Eng. J., 2015, 262, 595.

4 X. Guo, G. Fei, H. Su and L. Zhang, J. Phys. Chem. C, 2011, 115, 1608.

5 A. Olad and R. Nabavi, J. Hazard. Mater., 2007, 147, 845.

6 T. Zhou, C. Li, H. Jin, Y. Lian and W. Han, ACS Appl. Mater. Interfaces, 2017, 9, 6030.

7 A. G. Yavuz, E. Dincturk-Atalay, A. Uygun, F. Gode and E. Aslan, Desalination, 2011, 279, 325.

8 Q. Li, L. Sun, Y. Zhang, Y. Qian and J. Zhai, Desalination, 2011, 266, 188.

9 G. Sharma, M. Naushad, A. Al-Muhtaseb, A. Kumar, M. R. Khan, S. kalia, Shweta, M. Bala and A. Sharma, Int. J. Biol. Macromol., 2017, 95, 484.

10 S. Zhang, M. Zeng, W. Xu, J. Li, J. Li, J. Xu and X. Wang, Dalton Trans., 2013, 42, 7854.

11 G. Wang, Y. Hua, X. Su, S. Komarneni, S. Ma and Y. Wang, Appl. Clay Sci., 2016, 124, 111.

12 J. Yang, M. Yu and W. Chen, J. Ind. Eng. Chem., 2015, 21, 414. 13 W. Jiang, Q. Cai, W. Xu, M. Yang, Y. Cai, D. D. Dionysiou and K. E. O'Shea, Environ. Sci. Technol., 2014, 48, 8078.

14 Y. Zou, X. Wang, A. Khan, P. Wang, Y. Liu, A. Alsaedi, T. Hayat and X. Wang, Environ. Sci. Technol., 2016, 50, 7290.

15 J. Li, X. Wang, G. Zhao, C. Chen, Z. Chai, A. Alsaedi, T. Hayat and X. Wang, Chem. Soc. Rev., 2018, 47, 2322.

16 S. Yu, X. Wang, H. Pang, R. Zhang, W. Song, D. Fu, T. Hayat and X. Wang, Chem. Eng. J., 2018, 333, 343.

17 P. Gu, S. Zhang, X. Li, X. Wang, T. Wen, R. Jehan, A. Alsaedi, T. Hayat and X. Wang, Environ. Pollut., 2018, 240, 493.

18 G. Zhao, X. Huang, Z. Tang, Q. Huang, F. Niua and X. Wang, Polym. Chem., 2018, 9, 3562.

19 H. Chen, J. Dou and H. Xu, Appl. Surf. Sci., 2017, 425, 728.

20 Y. Jiang, Z. Liu, G. Zeng, Y. Liu, B. Shao, Z. Li, Y. Liu, W. Zhang and Q. He, Environ. Sci. Pollut. Res., 2018, 25, 6158. 21 V. Mazeiko, A. K. Minkstimiene, A. Ramanaviciene, Z. Balevicius and A. Ramanavicius, Sens. Actuators, B, 2013, 189, 187.

22 S. H. Qiu, C. Chen, W. R. Zheng, W. Li, H. C. Zhao and L. P. Wang, Synth. Met., 2017, 229, 39. 
23 M. Mohsennia, M. M. Bidgoli, F. A. Boroumand and A. M. Nia, J. Mater. Sci. Eng. B, 2015, 197, 25.

24 M. A. Moussa, M. H. A. Rehim, S. A. Khairy, M. A. Soliman, A. M. Ghoneim and G. M. Turky, Synth. Met., 2015, 209, 34.

25 Q. Li, L. Sun, Y. Zhang, Y. Qian and J. Zhai, Desalination, 2011, 266, 188.

26 D. Moon, M. Ezuka, T. Maruyama, K. Osakada and T. Yamamoto, Macromol. Chem. Phys., 1993, 194, 3149.

27 R. Karthik and S. Meenakshi, Int. J. Biol. Macromol., 2014, 67, 210.

28 J. J. Alcaraz-Espinoza, A. E. Chavez-Guajardo, J. C. MedinaLlamas, C. A. S. Andrade and C. P. de Melo, ACS Appl. Mater. Interfaces, 2015, 7, 7231.

29 M. Bhaumik, A. Maity, V. V. Srinivasu and M. S. Onyango, Chem. Eng. J., 2012, 181, 323.

30 J. Q. Wang, K. Pan, E. P. Giannelis and B. Cao, RSC Adv., 2013, 3, 8978.

31 N. Wang, Y. Chen, J. Y. Ren, X. Y. Huang, X. Y. Chen, G. D. Li and D. Q. Liu, J. Polym. Res., 2017, 24, 42.

32 D. Xu, S. Yan, W. Weng and R. Xiao, RSC Adv., 2016, 6, 44723.

33 X. Luo, A. J. Killard, A. Morrin and M. R. Smyth, Chem. Commun., 2007, 30, 3207.

34 B. K. Kuila and M. Stamm, J. Mater. Chem., 2010, 20, 6086.

35 C. J. Weng, Y. L. Chen, Y. S. Jhuo, L. Y. Li and J. M. Yeh, Polym. Int., 2013, 62, 774.

36 H. D. Tran, J. M. D'Arcy, Y. Wang, P. J. Beltramo, V. A. Strong and R. B Kaner, J. Mater. Chem., 2011, 21, 3534.

37 W. Chen, R. B. Rakhi and H. N. Alshareef, J. Mater. Chem. A, 2013, 1, 3315.

38 Q. Hu, C. Guo, D. Sun, Y. Ma, B. Qiu and Z. Guo, ACS Sustainable Chem. Eng., 2017, 5, 11788.

39 S. Zhang, M. Zeng, W. Xu, J. Li, J. Li, J. Xu and X. Wang, Dalton Trans., 2013, 42, 7854.

40 D. Z. Chen, S. P. Yi, W. B. Wu, Y. L. Zhong, J. Liao, C. Huang and W. J. Shi, Polymer, 2010, 51, 3867.

41 Z. Zhang, T. Gao, S. Si, Q. Liu, Y. Wu and G. Zhou, Chem. Eng. J., 2018, 343, 207.

42 J. Huang and R. B. Kaner, Angew. Chem., 2004, 116, 5941.

43 F. Guo, Q. Liu and H. Mi, Mater. Lett., 2016, 163, 115.

44 R. Ullah, H. Ullah, A. A. Shah, B. Bilal and K. Ali, J. Mol. Struct., 2017, 1127, 734.

45 D. Moon, M. Ezuka, T. Maruyama, K. Osakada and T. Yamamoto, Macromol. Chem. Phys., 1993, 194, 3149.

46 J. Germain, J. M. J. Frechet and F. Svec, J. Mater. Chem., 2007, 47, 4989.

47 V. Sharma, A. Sahoo, Y. Sharma and P. Mohanty, RSC Adv., 2015, 5, 45749.

48 T. Li, Z. Qin, B. Liang, F. Tian, J. Zhao, N. Liu and M. Zhu, Electrochim. Acta, 2015, 177, 343.

49 Y. Wu, D. Wang, L. Li, W. Yang, S. Feng and H. Liu, J. Mater. Chem. A, 2014, 2, 2160.
50 M. E. Abdelhamid, G. A. Snook and A. P. O'Mullane, Langmuir, 2016, 32, 8834.

51 M. Saad, H. Tahir, J. Khan, U. Hameed and A. Saud, Ultrason. Sonochem., 2017, 34, 600.

52 Y. Yan, Q. Cheng, Z. Zhu, V. Pavlinek, P. Saha and C. Li, J. Power Sources, 2013, 240, 544.

53 X. Wang, J. Deng, X. Duan, D. Liu, J. Guo and P. Liu, J. Mater. Chem. A, 2014, 2, 12323.

54 T. T. Luo, X. K. Tian, C. Yang, W. J. Luo, Y. L. Nie and Y. X. Wang, J. Agric. Food Chem., 2017, 65, 7153.

55 K. Gong, Q. Hu, Y. Xiao, X. Cheng, H. Liu, N. Wang, B. Qiu and Z. Guo, J. Mater. Chem. A, 2018, 6, 11119.

56 Q. Liu, Q. Z. Liu, W. Ma, W. L. Liu, X. X. Cai and J. S. Yao, Colloids Surf., A, 2016, 511, 8.

57 Q. Liu, Q. Liu, Z. Wu, Y. Wu, T. Gao and J. Yao, ACS Sustainable Chem. Eng., 2017, 5, 1871.

58 C. Lei, X. Zhu, B. Zhu, C. Jiang, Y. Le and J. Yu, J. Hazard. Mater., 2017, 321, 801.

59 M. O. Ansari, R. Kumar, S. A. Ansari, S. P. Ansari, M. A. Barakat, A. Alshahrie and M. H. Cho, J. Colloid Interface Sci., 2017, 496, 407.

60 M. Bhaumik, V. K. Gupta and A. Maity, J. Environ. Chem. Eng., 2018, 6, 2514.

61 T. Wen, Q. Fan, X. Tan, Y. Chen, C. Chen, A. Xu and X. Wang, Polym. Chem., 2016, 7, 785.

62 J. Wang, X. Wang, G. Zhao, G. Song, D. Chen, H. Chen, J. Xie, T. Hayat, A. Alsaedi and X. Wang, Chem. Eng. J., 2018, 334, 569.

63 W. Cheng, C. Ding, X. Wang, Z. Wu, Y. Sun, S. Yu, T. Hayat and X. Wang, Chem. Eng. J., 2016, 293, 311.

64 J. Wang, P. Wang, H. Wang, J. Dong, W. Chen, X. Wang, S. Wang, T. Hayat, A. Alsaedi and X. Wang, ACS Sustainable Chem. Eng., 2017, 5, 7165.

65 T. Wen, J. Wang, S. Yu, Z. Chen, T. Hayat and X. Wang, ACS Sustainable Chem. Eng., 2017, 5, 4371.

66 Z. Chen, D. Wei, Q. Li, X. Wang, S. Yu, L. Liu, B. Liu, S. Xie, J. Wang, D. Chen, T. Hayat and X. Wang, J. Cleaner Prod., 2018, 181, 745.

67 J. Wang, Y. Liang, Q. Jin, J. Hou, B. Liu, X. Li, W. Chen, T. Hayat, A. Alsaedi and X. Wang, ACS Sustainable Chem. Eng., 2017, 5, 5550.

68 M. Bhaumik, H. J. Choi, M. P. Seopela, R. I. McCrindle and A. Maity, Ind. Eng. Chem. Res., 2014, 53, 1214.

69 J. Li, T. Peng, Y. Zhang, C. Zhou and A. Zhu, Sep. Purif. Technol., 2018, 201, 120.

70 T. Zhou, C. Li, H. Jin, Y. Lian and W. Han, ACS Appl. Mater. Interfaces, 2017, 9, 6030.

71 G. Yang, L. Tang, Y. Cai, G. Zeng, P. Guo, G. Chen, Y. Zhou, J. Tang, J. Chen and W. Xiong, RSC Adv., 2014, 4, 58362.

72 C. Zhu, F. Liu, L. Song, H. Jiang and A. Li, Environ. Sci.: Nano, 2018, 5, 487. 